\title{
Epigenetic Regulation of miRNA Expression in Malignant Mesothelioma: miRNAs as Biomarkers of Early Diagnosis and Therapy
}

\author{
Marco Tomasetti ${ }^{1 *}$, Simona Gaetani ${ }^{1}$, Federica Monaco ${ }^{1}$, Jiri Neuzil ${ }^{2,3}$ and \\ Lory Santarelli ${ }^{1 *}$
}

' Section of Occupational Medicine, Department of Clinical and Molecular Sciences, Polytechnic University of Marche, Ancona, Italy, ${ }^{2}$ Mitochondria, Apoptosis and Cancer Research Group, School of Medical Science, Griffith University, Southport, QLD, Australia, ${ }^{3}$ Molecular Therapy Group, Institute of Biotechnology, Czech Academy of Sciences, Prague, Czechia

\section{OPEN ACCESS}

Edited by: Yuen Yee Cheng,

Asbestos Diseases Research

Foundation, Australia

Reviewed by:

K. Shilo,

The Ohio State University,

United States

Michael W. Y. Chan

National Chung Cheng

University, Taiwan

*Correspondence:

Marco Tomasett

m.tomasetti@staff.univpm.it

Lory Santarelli

I.santarelli@univpm.it

Specialty section:

This article was submitted to

Thoracic Oncology,

a section of the journal

Frontiers in Oncology

Received: 01 July 2019 Accepted: 07 November 2019 Published: 29 November 2019

Citation:

Tomasetti M, Gaetani S, Monaco F, Neuzil J and Santarelli L (2019)

Epigenetic Regulation of miRNA

Expression in Malignant

Mesothelioma: miRNAs as Biomarkers

of Early Diagnosis and Therapy.

Front. Oncol. 9:1293

doi: 10.3389/fonc.2019.01293
Asbestos exposure leads to epigenetic and epigenomic modifications that, in association with ROS-induced DNA damage, contribute to cancer onset. Few miRNAs epigenetically regulated in MM have been described in literature; miR-126, however, is one of them, and its expression is regulated by epigenetic mechanisms. Asbestos exposure induces early changes in the miRNAs, which are reversibly expressed as protective species, and their inability to reverse reflects the inability of the cells to restore the physiological miRNA levels despite the cessation of carcinogen exposure. Changes in miRNA expression, which results from genetic/epigenetic changes during tumor formation and evolution, can be detected in fluids and used as cancer biomarkers. This article has reviewed the epigenetic mechanisms involved in miRNA expression in MM, focusing on their role as biomarkers of early diagnosis and therapeutic effects.

\section{Keywords: malignant mesothelioma, epi-miRNAs, miR-126, epigenetic biomarkers, early diagnosis}

\section{INTRODUCTION}

Malignant mesothelioma (MM) is an aggressive malignancy, and its origin is largely associated with exposure to asbestos (1). Furthermore, asbestos exposure also increases the risk of lung cancers and a number of non-malignant diseases including pleural plaques, pleural effusions, and asbestosis (2). As a xenobiotic substance, asbestos contributes to the alteration of the genetic and epigenetic landscape (3). DNA is wrapped around histones that protect and regulate the packed DNA. This structure, chromatin, can be condensed and "closed," a state associated with transcriptional repression, or it can be "open," a state which allows proteins to access the DNA and thus inducing gene transcription. The chromatin structure is regulated and controlled by various post-transcriptional modifications, identified as epigenetic changes, which are catalyzed by a plethora of enzymes. The writers, erasers, and readers are enzymes involved in adding, removing, and recognizing, respectively, these post-transcriptional modifications. The methyltransferases and acetyltransferases act as writers, while the deacetylase and demethylase capable of removing acetyl and methyl groups are classified as erasers. Finally, the readers govern DNA transcription by binding to these modifications. 
Altered DNA methylation is mainly related to increased reactive oxygen species (ROS). ROS are generated either directly by iron linked to asbestos fibers or indirectly by inflammatory cells such as the alveolar or peritoneal macrophages acting on asbestos fibers during their passage through the lungs (4). Both ROS-induced mechanisms are involved in methylation and demethylation reactions. ROS induce hypermethylation of gene promoters via a Snail-dependent pathway by recruiting histone deacethylase 1 (HDAC1) and DNA methyl transferase 1 (DNMT1), linking DNA methylation and histone modification (5). Alternatively, ROS oxidize 5-methylcytosine to produce 5-hydroxymethylcytosine (6). This modification, mediated by the ten-eleven translocation methylcytosine dioxygenase (TET) family enzymes, is involved in the process of active demethylation of 5-hydroxymethylcytosine and is responsible for enhancing the transcriptional activity (7).

Changes in DNA methylation and histone modifications lead to silencing of tumor suppressor genes and genomic instability. It is well-established that small non-coding RNAs (miRNAs) are epigenetic modulators and that they themselves can be modulated by epigenetic changes. Alterations of miRNA expression have been reported to link exposure to environmental toxic agents with their pathological consequences, including cancer onset and progression. Asbestos exposure induces early changes in the miRNA machinery; therefore, altered miRNA levels can be proposed as biomarkers of early biological effects. The epigenome is dynamic as well as reversible. Reversible miRNA alterations represent an adaptive mechanism to environmental exposure, while the irreversibility reflects the inability of the cells to restore the physiological miRNA level despite the cessation of exposure to carcinogens. Therefore, it is plausible that miRNA dysregulation induced by carcinogens is predictive of cancer development only when these miRNA alterations become irreversible (8). The change from reversibility to irreversibility of miRNA alterations depends on the duration of the exposure. Long-term asbestos exposure is required to induce asbestos-related malignancies, and the persistence of fibers in the pleura may induce irreversible loss of miRNA function as a result of homozygous deletions of miRNA genes. In addition, the exposure dose also affects miRNA alterations, indicating that early miRNA alterations are affected by both the intensity and the duration of the exposure. While various miRNAs have been found to be deregulated in MM, few miRNAs have been described to be regulated by an epigenetic mechanism. Here, we have reviewed the epigenetic mechanisms involved in miRNA expression in MM, focusing on their role as biomarkers of early diagnosis and on their therapeutic effects.

\section{EPIGENETIC REGULATION IN MALIGNANT MESOTHELIOMA}

All forms of asbestos induce carcinogenicity involving both direct (oxidative stress) and indirect (chronic inflammation) mechanisms. Oxidative stress induced by free radical species (ROS) is considered to be one of the trigger for asbestos-induced pathogenesis. ROS as DNA-damaging agents increase mutation rates and promote malignant transformation, and they also act as signal mediators in redox signaling, which has an impact on several signaling pathways (9). These changes entail DNA oxidation events, post-translational modifications of histones proteins, and DNA methylation. The etiology of MM is associated with genomic mutations but also epigenetic errors leading to dysregulation of gene expression (Figure 1).

\section{Histone Modifications}

DNA is condensed in a complex represented by chromatin, and it is comprised of histones and non-histone proteins. The histone family includes $\mathrm{H} 1, \mathrm{H} 2 \mathrm{~A}, \mathrm{H} 2 \mathrm{~B}, \mathrm{H} 3$, and $\mathrm{H} 4$, whose covalent modifications have important roles in regulating chromatin dynamics and gene expression. For gene transcription to occur, DNA must be accessible to transcription factors and/or enhancers. The phosphorylation of histones endows them with reduced affinity for DNA, which may contribute to chromatin decondensation, thus allowing for the access of proteins needed for transcription. Phosphorylation of histones has been reported to be linked to DNA damage and ligation.

The acetylation of histones contributes to the expression of genes through transcription activation by changing condensed chromatin into a more relaxed structure, thereby recruiting components of the transcriptional machinery. This posttranslational modification is catalyzed by acetyltransferases and deacetylases by means of the acetylation/deacylation of lysine residues. There are three major families of histone acetyltransferases (HATs) and two families of lysine deacetylases, the $\mathrm{Zn}^{2+}$-dependent histone deacetylases (HDACs) and the nicotinamide adenine dinucleotide $\left(\mathrm{NAD}^{+}\right)$-dependent sirtuins $(10,11)$.

Generally, the acetylation of histones induces transcription activation, while histone methylation, catalyzed by Ezh2 (the catalytic activity of the PRC2 complex), can promote either activation or repression, based on the targeted residue within a particular histone (12). Methylation is a reversible process that is enzymatically regulated; methyl groups can be removed by demethylases of the JMJD2 subfamily, which selectively remove methyl groups from histone 3 lysine 9 (H3K9) (13). The removal of methyl groups is accomplished by successive oxidations of methylated cytosine by specific DNA hydroxylase enzymes in conjunction with the DNA base excision repair machinery. Oxidative stress induced by asbestos exposure transiently alters the epigenetic programmed process by affecting the activity of enzymes responsible for the demethylation and deacetylation of histones (14). ROS catalyzed via Fenton reaction in the presence of Fe (II) linked to the presence of asbestos fibers can increase histone methylation that may be attributed to the inhibition of histone demethylase activity, as previously reported $(15,16)$.

Previous studies have shown that Poly(ADP-ribose) polymerase-1 (PARP1) is involved in asbestos-induced DNA damage and repair $(17,18)$. Asbestos activates PARP1 to repair DNA in mesothelial cells; however, it was proposed that exposure to asbestos inhibits its activity, which results in higher DNA instability, thus causing malignant transformation (19).

PARP1 is responsible for most cellular poly(ADPribosyl)ation. PAR generation (PARylation) is another covalent 


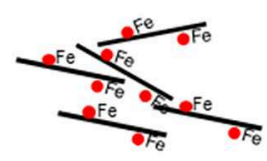

Asbestos

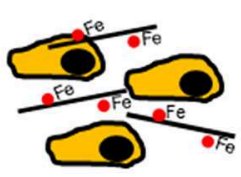

Mesothelial cells

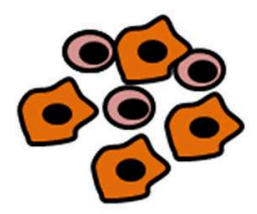

Macrophage

inflammatory cells

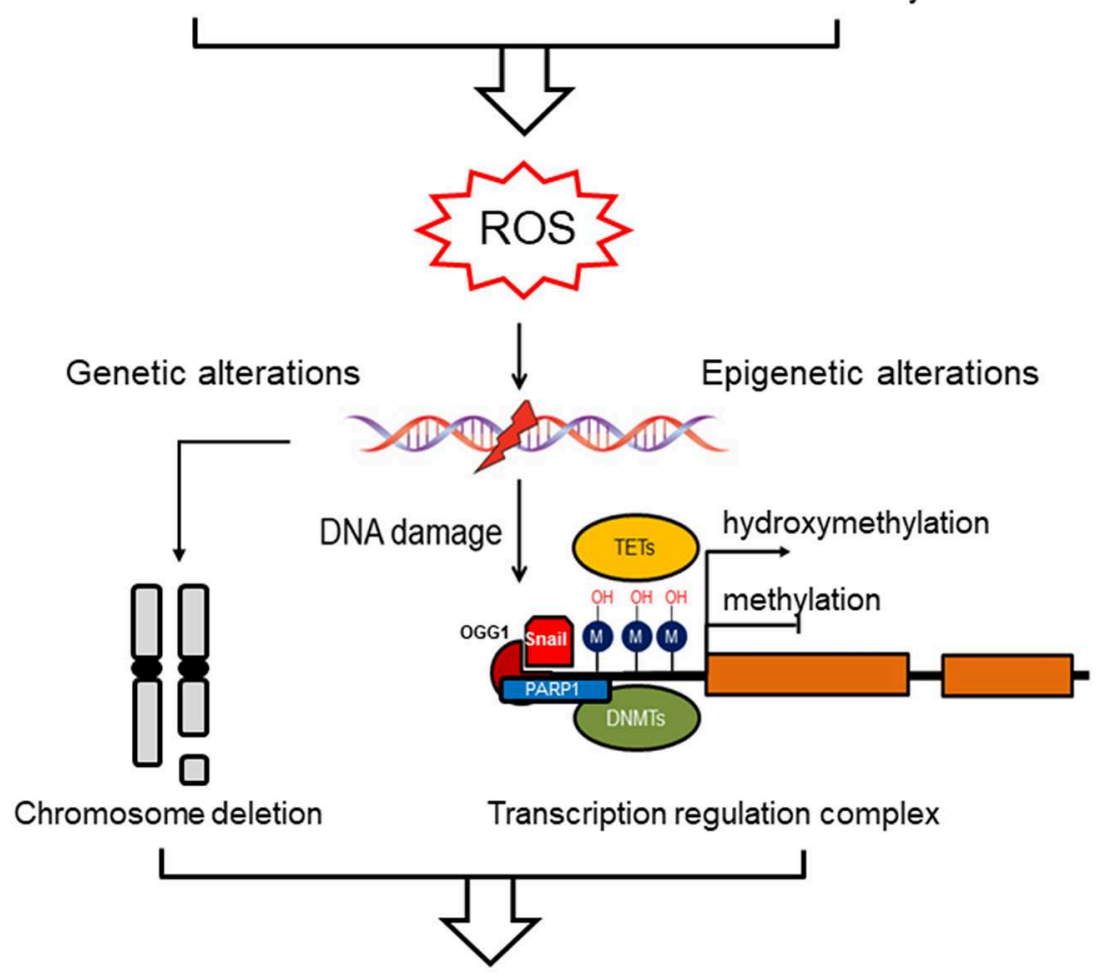

$\checkmark$

Malignant transformation

FIGURE 1 | Asbestos induces genomic/epigenomic alterations driving malignant mesothelioma. Asbestos exposure induces ROS formation directly via the iron-induced Fenton reaction or indirectly by chronic inflammation (mesothelial cells and macrophages inflammatory cells). ROS exposure induces methylation of the gene promoter via a specific recognition site to which DNMT1 and PARP1 are recruited, linking DNA damage and DNA methylation. Alternatively, prolonged ROS exposure induces demethylation by oxidizing the 5-methycytosine to produce 5-hydroxymethylcytosine, which is catalyzed by ten-eleven translocation methylcytosine dioxygenase (TET) family of enzymes. Hypomethylation of genomic DNA is associated with genomic instability, which in combination with genetic alterations (chromosome deletion), both contribute to malignant transformation.

post-translational modification; here, adenosine diphosphate (ADP)-ribose moiety from $\mathrm{NAD}^{+}$is transferred onto specific amino acid residues of acceptor proteins or onto pre-existing protein-linked ADP-ribose units. The PARylation of histones has been reported to decrease their affinity for DNA and to alter chromatin structure, therefore affecting several chromatindependent processes. The activity of PARP1 has been shown to be stimulated considerably due to the presence of various activators, including DNA damage (20). The role of PARP1 in remodeling chromatin overlaps with its role in DNA repair. Following DNA damage, PARP1 is rapidly recruited to the sites of damage and catalyzes PARylation, which results in the addition of PAR chains onto itself and a variety of acceptor proteins, including histones. This is a very rapid process; however, PAR generated following stress, which can include metabolic and genotoxic or oncogenic stressors, is rapidly degraded by poly(ADP-ribose) glycohydrolase (PARG), which cleaves the ribose-ribose bonds of PARs. The dynamic PARPs/PARG activity maintains the genomic methylation pattern. PARP1 can also participate in the regulation of DNA methylation by inhibiting the activity of DNA methyltransferases (DNMTs).

\section{DNA Methylation}

DNA methylation involves the covalent addition of methyl groups from cytosine to $\mathrm{CpG}$ dinucleotides that are concentrated in CpG islands (CGI). CGI are mainly located at annotated transcription start site (TSS) within gene bodies (intragenic) or between genes (intergenic), which are in a non-methylated state when the corresponding gene is transcriptionally active. The CpGs outside of the TSS that are involved in transcriptional 
initiation during development are methylated, leading to stable gene silencing. The CGI methylation is not the initiating event in gene silencing, but it acts to block in the silent state (21). More specifically, about $80 \%$ of the CpG residues that are not within the CGIs are methylated, while CGIs are, as a rule, free of methylation (22).

DNA methylation is related to the downregulation of gene expression. Silencing of CGI promoters by methylation is mediated by DNMT1, which preferentially target the "hemimethylated" DNA and directs the addition of a methyl group to the $5^{\prime}$ carbon position of the cytosine ring $(5 \mathrm{mC})$. DNMT1 recognizes hemimethylated DNA and is responsible for the maintenance of DNA methylation patterns during DNA replication, while DNMT3A and DNMT3B function as de novo methyltransferases, which add a methyl group to the previously unmodified DNA (23). Methylated DNA can prevent the binding of a particular transcription factor (TF) to the promoter; DNA methylation can also create binding sites for proteins that specifically recognize methylated DNA. However, several studies reported that methylation status did not correlate with gene expression, and about $37 \%$ of genes showed an inverse correlation. A promoter with low CpG density or without $\mathrm{CpG}$ in the $5^{\prime}$-UTRs might be subject to transcriptional regulation via DNA methylation, or hypermethylated CpGcontaining promoters might be transcriptionally active $(24,25)$. It has been postulated that methylation may play a permissive role by establishing chromatin structure changes, thus allowing transcriptional factors or histone modifications to regulate gene transcription. Nevertheless, some limitations of the methods used for the detection of DNA Methylation have to be taken in account. The method routinely used to detect DNA methylation in a whole genome or $\mathrm{CpG}$ is the DNA immunoprecipitation microarray or sequencing (MeDIP-chip/seq), which utilizes anti-methylcytosine antibodies to immunoprecipitate DNA that contains highly methylated CpG sites. The MeDIP-chip/seq has been widely used for analyses of methylated DNA in the different targets; however, it is considered low coverage due to the limit of $\mathrm{CpG}$ containing recognition sites. Another inherent limitation of $\mathrm{MeDIP}$-chip/seq is its lower resolution, which leads to artifacts and misleading results (26).

Accordingly, it was reported that the CpG density in the promoter determined how DNA methylation affected gene expression; high $\mathrm{CpG}$ density was often found in promoter regions of genes and was usually unmethylated. Methylation of these CGIs resulted in transcriptional silencing (27). DNA methylation is a highly dynamic process where the DNA demethylation process plays a central role. Active DNA demethylation involves methylcytosine dioxygenase (TET) that converts $5 \mathrm{mC}$ to 5 -hydroxymethylcytosine $(5 \mathrm{hmC})$. The oxidized $5 \mathrm{hmC}$ derivatives represent short-lived intermediates in the active demethylation process, and they also serve as stable epigenetic changes that exert distinctive regulatory roles (28).

Asbestos-induced ROS formation may promote global hypomethylation in cells by triggering the expression of TET enzymes, thus avoiding interference of DNMT (29). The global hypomethylation of the $\mathrm{CpG}$ residues that do not form CGI was found in cancer tissues, while hypermethylation was observed within promoters, leading to aberrant transcription initiation, and genome instability $(22,30)$. Although hypomethylation of large genome domains is frequent, it is not clear whether these effects are a primary or secondary effect in cancer. Interestingly, de novo methylation may potentially cause gene silencing, which contributes to the initiation of tumorigenesis. Prolonged ROS stress was found to induce methylation of the gene promoter involving Snail, a master regulatory transcription factor regulating organogenesis (5). However, the "primary epimutations" are rare, as most de novo methylation events are associated with DNA sequence changes, and these mutations are likely to be the primary genetic trigger in carcinogenesis $(31,32)$.

\section{EPIGENETICALLY REGULATED miRNAs IN MALIGNANT MESOTHELIOMA}

MicroRNAs (miRNAs) are short double-stranded non-coding RNAs ( $\sim 22$ nucleotides) that regulate gene expression at the post-transcriptional level. MiRNAs are transcribed in the nucleus as multiple stem loop structures (primary miRNAs). The primary miRNAs are processing into pre-miRNAs by the RNase III enzyme DROSHA, and they are then transported to the cytoplasm where a dicer enzyme removes hairpin structure yielding a 21 base pair miRNA duplex. The mature miRNAs are then incorporated into the RNA-induced silencing complex (RISC) comprising a RNA-binding protein (RBP), such as the Argonaute (Ago) protein, and several auxiliary factors. The binding of miRNAs to their targets is mediated by the hybridization of 7-8 nucleotides of the miRNAs to their complementary nucleotides in the $3^{\prime}$-untranslated regions of their targets. The RNA-binding domains allow RBP to specifically target RNAs resulting in translational inhibition or degradation of target mRNAs, thereby inhibiting gene expression. It has been established that one miRNA can bind to more than one species of mRNA target. On the other hand, multiple species of miRNAs can bind to the same mRNA targets and enhance translational inhibition (33).

Similarly to genes coding for proteins, the expression of miRNAs is regulated by both genetic and epigenetic mechanisms. DNA hypomethylation/hypermethylation and histone modifications are involved in the regulation of the expression of miRNA promoters. It has been reported that miRNA gene methylation is one order magnitude more frequent than that of the protein-encoding genes (34). A high proportion of miRNA is embedded in CGIs susceptible to methylation, and they are therefore highly prone to be epigenetically regulated (35). MiRNAs that are located in the tumor-associated genomic regions (36) can play two distinct roles in malignancy, either as oncogenes or as tumor suppressors (37). According to the miRNA database (38), most miRNAs (62\%) are intragenic, i.e., located within introns or exons of protein-encoding genes, while $38 \%$ are intergenic, i.e., located in the regions between annotated genes. The transcription of intergenic miRNA is independent of coding genes having their own transcription regulatory elements, such as the promoter, the transcriptional start site, and the terminal signals. Conversely, intragenic miRNAs are 
co-expressed with their host genes, although some miRNAs show no obvious correlation with their host gene $(39,40)$. A number of intronic miRNAs regulate the expression by their own independent promoters. In addition to this, genetic alterations by asbestos involves methylation silencing, and various genes have been found to be methylated in malignant mesothelioma (41).

The methylation profile differred among the histological types, and the mesothelial sarcomatoid tumors (SMM) featured hypermethylation characterized by elevated levels of $5 \mathrm{mC}$ (42). The hypermethylated KAZALD1 gene was found in SMM (43). On the other hand, the loss of BRCA1-associated protein1 (BAP1) was mainly observed in epithelial MM (EMM), showing superior diagnostic accuracy in EMM to that in the other two subtypes (44). BAP1 is the most commonly mutated gene in $M M$, and its expression is altered by both genetic and epigenetic mechanisms $(45,46)$. BAP1 affects gene transcription by post-translational modifications through ubiquitination changes (47). Inactivation of $B A P 1$ cooperates with the loss of either $C D K N 2 A / 2 B$ (cyclin-dependent kinase inhibitor $2 \mathrm{~A} / 2 \mathrm{~B}$ ) or NF2 (neuriofibromin 2) to drive the development of $\mathrm{MM}$, highlighting its role in cell transformation (48). It has been reported that germline mutations of DNA repair genes, including $B A P 1$, predispose asbestos-exposed patients to $\mathrm{MM}(49,50)$. While the involvement of somatic BAP1 mutations in mesothelial tumorigenesis is well described, its epigenetic role is still controversial (51). By analyzing 22 sporadic MM biopsies, Nasu and colleagues found that BAP1 promoter methylation was not altered in MM (52). On the other hand, genomic profiling of $\mathrm{MM}$ identified recurrent mutations in the epigenetic regulatory gene $B A P 1$ (47). Rather than through genetic/epigenetic alterations, miRNAs may affect $B A P 1$ gene expression at a post-transcriptional level. A negative correlation was found between the levels of miR-31 and the BAP1 protein expression in lung cancer (53). The same authors identified miR-31 as a direct target of the BAP1 gene. Despite the loss of expression of miR-31 due to the deletion of the miR-31 gene in chromosome 9p21.3, which is a common aberration in aggressive forms of MM (54), an epigenetic mechanism has also been involved $(55,56)$, and its upregulation was associated with a worse prognosis in MM (57).

Various miRNAs have been found deregulated in MM, and their performance as diagnostic/prognostic markers in biological fluids has been extensively reviewed by Lo Russo et al. (58). Nevertheless, methods for the quantification and the type of samples used limit their clinical application. The use of an RNA high-throughput sequencing system may provide more reliable and reproducible data with higher clinical relevance.

On the other hand, few miRNAs that are epigenetically regulated in MM are described in the literature. The miR-34 family was found downregulated in MM by a mechanism that involves promoter methylation (59-61). Methylated miR-34 can be detected in serum samples, and its degree of methylation in circulating DNA has been associated with the development of MM (62).

Similarly, hypermethylation of the miR-145 and miR-126 promoter regions is responsible for the low levels of the miRNA in both malignant mesothelial tissues and mesothelioma cell lines (63-67). MiR-126 is epigenetically modulated in cancer including MM. MiR-126 is located in chromosome 9 (q34,3) within intron 7 of its host gene epidermal growth factorlike domain-containing protein 7 (EGFL7), a member of the epidermal growth factor (EGF)-like protein family. EGFL7 is highly expressed by and acts on endothelial cells, and, thus, its expression is highest when the endothelium is in an active, proliferating state $(68,69)$. Both miR-126 and EGFL7 could facilitate independent, albeit complementary mechanisms to regulate angiogenesis and to maintain vascular integrity (70). MiR-126 promotes vascular endothelial growth factor (VEGF)mediated signaling and angiogenesis by suppressing the Sproutyrelated EVH1 domain-containing protein 1 (SPRED1) and phosphoinositide-3-kinase regulatory subunit 2 (PI3KR2), both of which are involved in the inhibition of mitogen-activated protein kinase (MAPK) and PI3K signaling pathways $(71,72)$. On the other hand, miR-126 inhibits angiogenesis by the direct targeting of VEGF-A $(73,74)$. In addition, miR-126 is known to play a crucial role in tumor pathogenesis, where it acts as an oncosuppressor by inhibition of the PI3K/AKT pathway (75, 76). Further, MiR-126 was found to target ADAM9 (disintegrin and metalloproteinase domain-containing protein 9), which is highly expressed in cancer. Re-expression of miR-126 resulted in ADAM9 silencing in pancreatic cancer cells, thereby reducing cellular migration, invasion, and induction of the epithelial marker E-cadherin (77-79).

Several reports have indicated that miR-126 expression was downregulated in cancer tissues compared with non-tumor tissues (67), including MM (80-86), and its restoration impaired cell growth, migration, invasive properties, and tumorigenesis (87-91). Promoter methylation resulted in the silencing of miR126 in colorectal cancer $(92,93)$, breast cancer $(94)$, lung cancer (95, 96), esophageal squamous cell carcinoma (97), glioma (98), and MM (66). Hypermethylation of the CGI in EGFL7 intron 2, which harbors the S2 transcriptional initiation site of EGFL7 mRNA and miR-126, was found in MM and was found to be a significant prognostic factor associated with poor survival (66).

Activation of miR-126 by the inhibition of DNA methylation and histone deacetylation further confirmed the epigenetic mechanism $(65,92)$. Although miR-126 and the EGFL7 S2 were upregulated after treatment with chromatin-modifying drugs, a very low DNA methylation level was found in the promoter region in bladder and prostate tumors (65). A similar scenario was observed in MM where cancer tissue and its adjacent nonmalignant (NM) counterpart were analyzed for the methylation status of the EGFL7 S2 promoter region in relation to miR126 and EGFL7 expression. The downregulation of both miR126 and EGFL7 found in MM tissue was not related to any methylation changes within the EGFL7 S2 promoter (Gaetani et al., unpublished data), suggesting that miR-126 expression was regulated by structural changes of chromatin rather than by DNA methylation. On the other hand, high expression of PARP1 and DNMT1 was observed in malignant compared to non-malignant tissue. The expression of EGFL7 and miR-126 correlated positively with each other and correlated negatively with PARP1 and DNMT1 levels. In an "in-vitro" stromal model, MM H28 cells co-cultured with fibroblasts and endothelial cells 
increased PARP1 expression, leading to miR-126 and EGFL7 downregulation. Furthermore, knocking down PARP1 in MM H28 cells induced miR-126 and EGFL7 upregulation, which was associated with increased DNMT1 levels. These results point to the involvement of PARP1 and DNMT1 in miR-126 regulation in MM. Both DNMT1 and PARP1 are known to modulate chromatin structure; PARP1, in particular, associates with promoters of actively transcribed genes and exerts both positive and negative effects on gene transcription.

Our group reported that DNMT1 expression paralleled upregulation of PARP1, thereby supporting the role of PARP1 in protecting the DNMT1 promoter from methylation, as previously reported $(99,100)$. These findings indicate that increased expression of DNMT1 was responsible for the methylation of the EGFL7 promoter and the ensuing downregulation of miR-126. Aberrantly upregulated DNMT1 and the downregulation of miR-126 associated with promoter hypermethylation of its host gene EGFL7 were observed in esophageal squamous cell carcinoma (ESCC). Based on these findings, a regulatory DNMT1-miR-126 epigenetic circuit was proposed (97). However, we showed that the methylation status of the EGFL7 promoter cannot fully explain the modulation of miR-126 expression. This is supported by the notion that DNA methylation does not work alone, but occurs in the context of other epigenetic modifications, such as histone modifications, which constitute epigenetic regulatory miRNA expression.

Intriguingly, asbestos-exposed subjects showed a high miR126 level (86), and bronchial epithelial cells (BEAS-2B) exposed to asbestos showed increased expression of miR-126 and its host EGFL7 gene, which was associated with increased expression of DNMT1, and reduced expression of PARP1 in these cells. Notably, both under normal and pathological conditions, the lack of PARP1 resulted in increased DNMT1 expression and consequent miR-126 upregulation. Aberrant promoter methylation was found to contribute to the regulation of this gene. Evidence suggests that the repressive activity of DNMT1 may not be dependent only on DNA methylation, suggesting a "scaffolding" role for the protein to recruit other transcriptional repressive components (101). In this context, PARP1 is a part of a protein complex containing UHRF1 (ubiquitin-like, with PHD and RING finger domains 1), an epigenetic coordinator, and DNMT1 in which PARP1 regulates UHRF1-associated biological activities. A reduced UHRF1DNMT1 complex was observed in the absence of PARP1, and it did not significantly perturb the catalytic activity of DNMT1. However, PARP1 participates in the UHRF1mediated chromatin modifications required for gene silencing (102). A proposed model of the PARP1-UHRF1-DNMT1 complex in the regulation of miRNA expression is shown in Figure 2.

Alternatively, the TET family of proteins expressed in response to asbestos-induced oxidative stress may promote active demethylation of the EGFL7 promoter, thereby contributing to miR-126 accumulation. DNA methyltransferases (DNMT1, DNMT3A, and DNMT3B) in combination with TET proteins that catalyze demethylation have been previously reported to regulate stress-induced miR-126 expression (103).

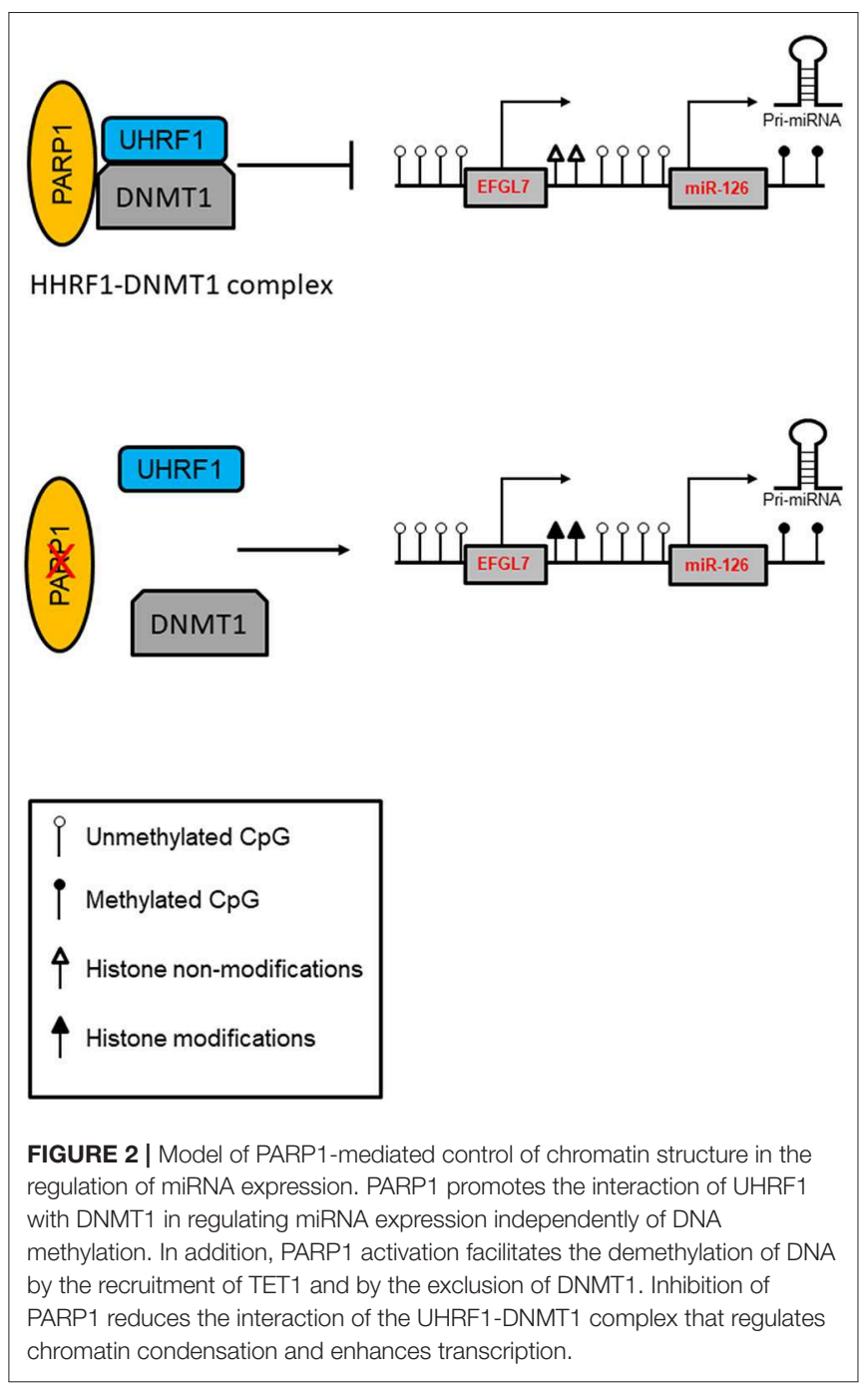

However, rather than methylation, PARP1 may orchestrate the expression of miR-126 by its upregulation of miR-126 in asbestos-exposed cells, while it may also downregulate miR126 in MM cells. High PARP1 expression has been observed both in asbestos-exposed subjects, and this is most probably a consequence of oxidative stress induced by asbestos. However, the PARP1 expression did not correlated with its activity. It has been proposed that exposure to asbestos inhibits the PARP1 activity, possibly resulting in higher DNA instability that can lead to malignant transformation (19).

miRNAs can be epigenetically regulated by DNA methylation and/or histone modifications. In turn, certain miRNAs directly target enzymatic effectors involved in epigenetic modulations (104), thus suggesting a regulatory circuit between epigenetic modulation and miRNAs, which could have a significant effect on transcription $(95,105)$. In ESCC, the overexpression of DNMT1 induced promoter hypermethylation of the miR-126 host gene, which resulted in decreased levels of miR-126. On the other hand, DNMT1 was suppressed by miR-126 overexpression (97). Similarly, it was found that members of the miR-29c 
family had a direct effect on DNMTs in MM (106), and it was demonstrated that these miRNAs also affected the demethylation pathway (107).

\section{MIRNA-INDUCED METABOLIC CHANGES AFFECT EPIGENETIC REGULATION IN MALIGNANT MESOTHELIOMA}

miRNAs are known to regulate epigenetics by affecting various metabolic processes either directly or indirectly $(108,109)$. The chromatin undergoes continuous modifications, which are dependent on intermediate metabolites, including acetyl$\mathrm{CoA}, \mathrm{ATP}, \mathrm{NAD}^{+}$, flavin adenine dinucleotide (FAD), $\alpha-$ ketoglutarate $(\alpha-K G)$, and uridine diphosphate (UDP). These metabolic intermediates can serve as cofactors or inhibitors of the enzymatic activity of chromatin modifiers, thereby coupling the chromatin structure with the metabolic state of the cell. For instance, IRS1, an adaptor protein mediating IGF-I/insulin signaling, which is involved in various pathological processes, is a target of miR-126 $(90,110)$. IRS1 integrates signaling from insulin receptors, insulin-like growth factor-1 receptor (IGF-1R), and many other cytokine receptors, leading to the activation of the PI3K-AKT. AKT promotes the shunting of mitochondrial citrate from the tricarboxylic acid (TCA) cycle to acetyl-CoA production by activation of ATP citrate lyase (ACLY). AcetylCoA forms are the universal substrate for the acetylation of histones. The histone acetylation is one of the best-characterized post-translational modifications. The HAT activity, which relies on intracellular levels of acetyl-CoA, connects metabolism to transcriptional regulation by chromatin dynamics. The high activity of pathways resulting in the formation of acetyl-CoA precursors, such as the IRS1-activating IGF-I/insulin signaling, is linked to histone hyperacetylation, which in turn promotes gene expression that modulates cell growth under these "favorable" conditions. Restoration of miR-126 in MM suppressed the IRS1/IGF/AKT pathway and inhibited ACLY, thus contributing to the decrease of acetyl-CoA-mediated histone acetylation (91).

MiR-126 reduced mitochondrial respiration in MM cells and induced the mitochondrial redox activity (MRA) as a result of increased intracellular reductants such as $\mathrm{FMNH}_{2}$, $\mathrm{FADH}_{2}$, and NADH/NADPH (90). These reducing elements are produced by aerobic glycolysis, and their consumption in the mitochondrial matrix is a consequence of altered homeostasis. The flux through glycolysis determines the $\mathrm{NAD}^{+} / \mathrm{NADH}$ ratio, which is important for the deacetylation activity of sirtuins (SIRTs). Another $\mathrm{NAD}^{+}$-dependent protein involved in chromatin remodeling is PARP1. The epigenetic alteration by PARP1 includes the maintenance of $\mathrm{H} 3 \mathrm{~K} 4 \mathrm{me} 3$ in the trimethylated form, a marker of permissive chromatin, resulting in the inhibition of the histone demethylase and histone deacetylase KDM5B and HDAC. This prevents the aberrant hypermethylation of CGI in the housekeeping gene promoters by DFNMT3a/b (111).

Intracellular ATP can be involved in the epigenetic regulation as well. The ATP level is above the $K_{m}$ value for most kinases that, in most cases, do have a direct effect on histone phosphorylation. However, some kinases, such as AMPK, which is activated by high AMP/ATP ratios that, in turn, are indicative of metabolic stress, can translocate to the nucleus and specifically phosphorylate histone $\mathrm{H} 2 \mathrm{~B}$ on serine 36 . AMPK-dependent $\mathrm{H} 2 \mathrm{~B}$ Ser36 phosphorylation is essential for transcription and survival in response to metabolic stress (112). The epigenetic regulation of miR-126 by metabolic changes in MM is documented in Figure 3.

It was proposed that environmental exposure affects the global epigenetic pattern by interfering with the metabolism by a mechanism that involves oxidative stress. Cancer metabolic rewiring could affect the availability of cofactors required for epigenetic changes and generate oncometabolites that act to modify the expression of epigenetic enzymes. On the other hand, epigenetic alteration modifies metabolism by affecting the expression of the relevant enzymes.

\section{EPIGENETIC MIRNAS AS BIOMARKERS OF MALIGNANT MESOTHELIOMA}

Epigenetic modifications are observed in early stage tumors; therefore, the detection of epigenetic miRNAs (epi-miRNAs) could be used as an epigenetic biomarker for early detection of cancer. Several microRNA signatures (miRscore) have been performed to identify candidate miRNAs with potential diagnostic and prognostic biomarkers $(58,113,114)$. Table 1 summarizes the most specific miRNAs reported by different groups (115, 117-121, 123-125).

Alteration of miRNA expression plays an important pathogenic role in linking carcinogen exposure and its pathological consequences, such as cell transformation. By evaluating the miRNA expression profile in lung cancer tissues and their normal counterparts of highly asbestos-exposed and non-exposed lung cancer patients, 13 deregulated miRNAs that were related to asbestos exposure were identified (126). Recently, Santarelli et al. proposed a panel of four miRNAs (miR-126, miR205, miR-222, and miR-520g) that were found to be implicated in asbestos-related malignant diseases (86). Notably, increased expression of miR-126 and miR-222 was found in subjects currently exposed to asbestos, such as workers involved in the maintenance and restoration of buildings containing asbestos. Conversely, subjects exposed to asbestos in the past did not show any changes in miRNA expression, suggesting a reversible mechanism. While the reversible miRNA alterations represent an adaptive response to acute carcinogen exposure, long-lasting exposure to carcinogens causes irreversible miRNA alterations that activate carcinogenic mechanisms. Notably, irreversible alterations of miRNA expression can result in cell transformation only when accompanied by other molecular changes. It has been established that the irreversible loss of miRNA in cancer is the result of chromosome deletion or epigenetic-induced silencing of miRNA host genes $(127,128)$. According to these notions, miRNAs show high sensitivity in detecting exposure to carcinogens and malignancy induced by the exposure itself, representing a general mechanism that links exposure to carcinogens with the pathological consequences (Figure 4). 


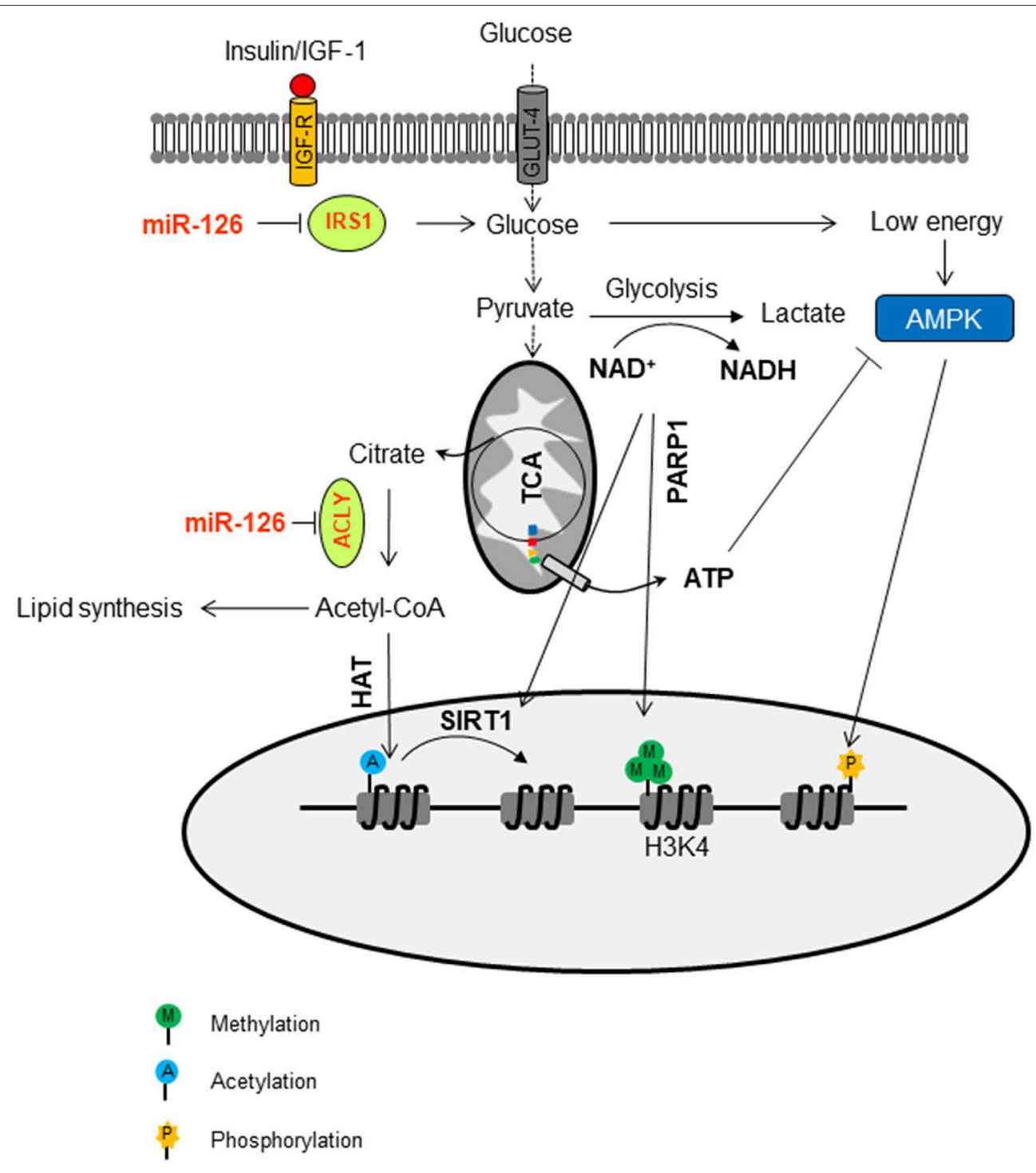

FIGURE 3 | Epigenetic regulation of miR-126 by metabolic changes in malignant mesothelioma. MiR-126 suppresses IRS1 by binding to its 3' -UTR, with ensuing inhibition of the insulin/IGF-1/AKT pathway. This contributes to the change of glucose metabolism. The flux trough glycolysis determines the NAD+/NADH ratio, which is involved in the activation of sirtuin histone deacetylases (SIRTs). The NAD+-dependent PARP1 is involved in the maintenance of H3K4me3 in the trimethylation form, a marker of permissive chromatin. The ATP/AMP ratio can activate AMPK, a kinase that can phosphorylate histones. In addition, miR-126 inhibits ATP citrate lyase (ACLY), thus increasing the cytosolic citrate, which is converted to acetyl-CoA and used as a donor for histone acetyltransferases (HAT)-mediated histone acetylation.

This is the case for miR-126 in MM, where its expression is modulated in response to asbestos exposure, promoting malignant transformation. MiR-126 expression increases as an adaptive response to asbestos exposure and may proceed to the loss of its expression as a consequence of DNA damage accumulation and chromosome deletion, thus leading to carcinogenesis. Activation of the miRNA machinery is an early event during exposure to carcinogens, thus representing a very sensitive biomarker of their early effect. As reported in Table 2, miR-126 showed an acceptable sensitivity $(71 \pm 12 \%)$ with a low specificity (54 $\pm 15 \%)$ to the differentiation of healthy subjects from patients with
MM. However, to complete the carcinogen process, the occurrence of other molecular events is required. Accordingly, multiple biomarkers of different molecular classes should be used to predict cancer development. In this context, the epigenetically regulated miR-126 and miR-145 (epimiRNAs) were combined with miR-143 and miR-652 in order to differentiate $\mathrm{MM}$ from non-neoplastic pleura and reactive mesothelial proliferations (82). Moreover, epi-miR126 has been associated with specific biomarkers of MM, such as soluble mesothelin-related proteins (SMRPs) (80). When combined with SMRPs, miR-126 indicates a better discriminatory ability to identify tumors in a population of 
TABLE 1 | MiRNAs with diagnostic and prognostic value and their targets in malignant mesothelioma.

\begin{tabular}{|c|c|c|c|c|c|}
\hline & & miRNA & Target genes & Cell function & References \\
\hline \multirow{4}{*}{\multicolumn{2}{|c|}{ DIAGNOSIS }} & $\mathrm{miR}-16$ & Bcl-2, CCND1 & Apoptosis, cell cycle & $(115,116)$ \\
\hline & & miR-103 & ICOS, SERBP1, FBXW11 & Transcription, genome integrity & $(117)$ \\
\hline & & miR-223 & $\begin{array}{l}\text { PARP1, MDM2, TP53, JNK signaling, } \\
\text { STMN1 }\end{array}$ & Cell motility, tubulin acetylation & (119) \\
\hline & & miR-625 & Unknown & - & $(120)$ \\
\hline \multirow{6}{*}{$\begin{array}{l}\text { PROGNOSIS- } \\
\text { DIAGNOSIS }\end{array}$} & & miR-193a & MCL1, PD-L1, E2F1, SRSF2, TYMS & Proliferation, apoptotic/necrotic & (122) \\
\hline & & $\mathrm{miR}-143$ & DNMT3A, FOSL2 & Proliferation, methylation & (82) \\
\hline & & miR-652 & Unknown & - & (82) \\
\hline & & miR-23a & Unknown & - & $(113)$ \\
\hline & & miR-31 & PPP6C & $\begin{array}{l}\text { Proliferation, migration, invasion, } \\
\text { colony formation }\end{array}$ & $(55-57,113)$ \\
\hline & & miR-126 & $\begin{array}{l}\text { CRK, PI3K/Akt, p85 } \beta \text {, IRS1, ADAM9, } \\
\text { VEGF, VCAM1, EGFL7, SOX-2 }\end{array}$ & $\begin{array}{l}\text { Proliferation, invasion, migration, } \\
\text { angiogenesis }\end{array}$ & $(65,82,90)$ \\
\hline \multirow{4}{*}{\multicolumn{2}{|c|}{ PROGNOSIS }} & miR-29c & DNMT1, DNMT3A & $\begin{array}{l}\text { Proliferation, migration, invasion, } \\
\text { colony formation, methylation }\end{array}$ & $(106,107)$ \\
\hline & & miR-21 & PARP1, MSLN & DNA repair & $(113,123,124)$ \\
\hline & & miR-30 & P53 & Tumor suppressor, cell cycle & (113) \\
\hline & & miR-221/222 & PTEN, TIMP3, p27Kip1, p57, Bim & Cell invasion, metastasis & $(113,125)$ \\
\hline
\end{tabular}

CCND1, cyclin D1-encoding gene; ICOS, inducible T-cell co-stimulator; SERBP1, SERPINE1 MRNA Binding Protein 1; FBXW11, F-box and WD repeat domain containing 1; PARP1, Poly(ADP-ribose) polymerase-1; MDM2, Mouse double minute 2 homolog; STMN1, Stathmin 1; KCNMA1, calcium-activated potassium channel subunit alpha 1; PD-L1, Programmed death-ligand 1; E2F1, E2F Transcription Factor 1; SRSF2, Splicing factor, arginine/serine-rich 2; TYMS, Thymidylate Synthetase; DNMT3A, DNA methyltransferase-3A, FOSL2, FoSrelated antigen 2; PPP6C, Protein Phosphatase 6 Catalytic Subunit; CDKN2, cyclin-dependent kinase inhibitor; NF2, neurofibromatosi tipo 2; OCT-4, octamer-binding transcription factor 4; ZEB1, Zinc Finger E-Box Binding Homeobox 1; IRS1, insulin receptor substrate-1; ADAM9, metalloproteinase domain-containing protein 9; VEGF, vascular endothelial growth factor; VCAM1, vascular cell adhesion molecule 1; EGFL7, epidermal growth factor-like domain-containing protein 7; SOX-2, Sex-determining region Y-box 2; MSLN, mesothelin; PTEN, prime time entertainment network; TIMP3, TIMP metallopeptidase Inhibitor 3.

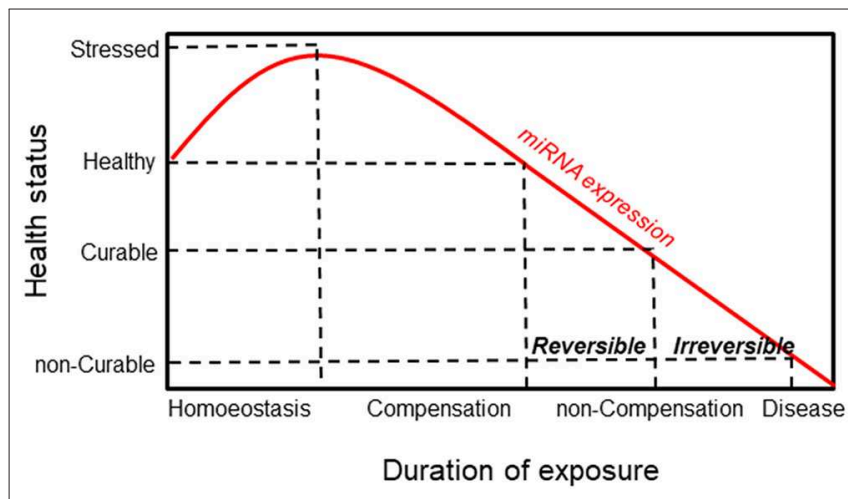

FIGURE 4 | Schematic responses of miRNA and healthy status to environmental exposure. MiRNA expression increases in response to exposure as an adaptive mechanism. This is followed by a compensation phase where miRNA expression is reversible (curable disease). Prolonged exposure induces a non-compensation phase, and the irreversibility of miRNA is associated with the development of the disease (non-curable disease).

subjects with high risk, suggesting that they have a potential role as predictive biomarkers.

Indeed, the combination of two circulating epigenetic biomarkers (methylated thrombomodulin and epi-miR-126)
TABLE 2 | Ability of miR-126 to distinguish healthy subjects from malignant mesothelioma patients.

\begin{tabular}{|c|c|c|c|c|}
\hline Studies & Sample & $\begin{array}{c}\text { Sensitivity } \\
(\%)\end{array}$ & $\begin{array}{l}\text { Specificity } \\
(\%)\end{array}$ & $\begin{array}{l}\text { AUC (area } \\
\text { under curve) }\end{array}$ \\
\hline Santarelli et al. (80) & Serum & - & - & $\begin{array}{l}0.701[0.542-0.851] \\
p=0.024\end{array}$ \\
\hline Tomasetti et al. (81) & Serum & 70 & 60 & $\begin{array}{l}0.894[0.503-0.968 \\
p=0.0001\end{array}$ \\
\hline Santarelli et al. (83) & Serum & 75 & 54 & $\begin{array}{l}0.710[0.568-0.822] \\
p=0.001\end{array}$ \\
\hline Santarelli et al. (86) & Serum & 62 & 30 & $\begin{array}{l}0.626[0.524-0.728] \\
p=0.018\end{array}$ \\
\hline Weber et al. (129) & Plasma & 59 & 72 & $\begin{array}{l}0.614 \text { [0.439-0.789], } \\
p<0.05\end{array}$ \\
\hline
\end{tabular}

with SMRPs for early MM diagnosis overcomes the limitations of using SMRPs alone (83). SMRPs are widely studied tumor markers for the early diagnosis of MM or for monitoring the response to treatment (130). The level of SMRPs can differentiate MM patients from healthy controls with a sensitivity of $60-70 \%$ and specificity of $90-100 \%$, and it can better discriminate controls from patients with advanced MM $(83,131)$. However, 
this correlation was found only in the $40-50 \%$ of epithelioid or biphasic MM histotypes and in the $30 \%$ of sarcomatoid MM. A meta-analysis study showed that, in patients suspected of having mesothelioma or high-risk subjects, a negative blood test for SMRPs did not exclude MM even at the high sensitivity threshold (1-1.5 nmol/l) (132). The poor sensitivity of SMRPs clearly limits its clinical value to early diagnosis and emphasizes the need for further biomarkers. The epigenetic biomarkers offer the advantage of increased sensitivity at the expense of specificity, which can be overcome by a combination with specific soluble proteins released directly from the tumor, such as SMRPs, osteopontin (pOPN), vimentin, fibulin-3, and other promising marker for the diagnosis (130).

MM is a highly fatal malignancy featuring rapid development. There are therefore some concerns about the use of biomarkers for its early detection and their impact on the survival of MM patients. The onset of MM is insidious; the diagnosis can be difficult, with clinical symptoms that can mimic many other diseases. Most patients therefore have advanced disease at presentation, which limits the efficacy of current therapies for $\mathrm{MM}$, and the overall prognosis remains poor. The optimal management of MM requires its early diagnosis (133). Although many miRNAs alone or in association with other molecules have been proposed, most of the candidate biomarkers have not been validated in pre-diagnostic samples. In a recent study, three specific miRNAs for MM, including epi-miR-126, were evaluated in pre-diagnostic MM (median of 9 months from the diagnosis). The candidate miRNAs either alone or in combination failed to detect MM, thus it was concluded that they were not feasible for the early detection of this cancer (129). It was reported that downregulation of miRNAs detected in the serum of MM patients was not linked to deregulation of these miRNAs within the tumor (134). It is plausible that the tumor has to reach a certain stage (size) for a specific effect on miRNA expression to be seen.

For instance, the expression of miR-126, which is mainly produced by endothelial cells, is affected not only by cancer but by also by other pathologies involving endothelial dysfunction, including type 2 diabetes and coronary artery disease $(67,135)$. Thus, the downregulation of circulating miRNAs is a non-specific response to the presence of neoplastic tissue. The diagnostic role of miRNAs is therefore limited, and only when combined with other markers (proteins, miRNA, DNA methylation, and non-coding RNA) may circular miRNA improve their diagnostic performance. While the diagnostic role of miRNAs is questionable, their role in the prediction of prognoses and response to therapy in MM is well established $(64,83)$.

\section{POTENTIAL THERAPEUTIC ROLE OF EPI-miRNAs}

Since miRNA can target multiple cell pathways, their use as a therapeutic approach may be important in cancer therapy. Various miRNAs (miR-16, miR-126, miR-145, and miR-193a$3 p$ ) and different delivery systems have been tested to inhibit MM tumor growth $(63,90,116,122)$. Both miR-126 and
miR-145 are epigenetically regulated, and treatment with the DNA methylation inhibitor 5-aza-2'-deoxycytidine (5-Aza-CdR) restored their expression and, consequently, inhibited cancer growth and invasion $(89,136)$. The enhanced expression of miR126 induced the complex metabolic reprogramming of MM, resulting in tumor suppression $(90,91)$. Similarly, ectopic miR145 inhibited proliferation, clonal growth, and migration of MM cells, thus reducing in vivo tumorigenicity (63). These findings imply that miR-126 and miR-145 have a potential as miRNAbased therapeutic targets for MM.

The only clinical trial (NCT02369198) performed in human MM patients was the phase I, open-label, dose-escalation study. The drug was designed with the aim to restore miR16 , which is frequently downregulated in MM (137). MiR-16 (TargomiR) administrated by the minicell-based formulation (EnGeneIC Dream Vectors) was well-tolerated by MM patients. The observed adverse drug reactions were transient lymphopenia (96\%), hypophosphataemia (65\%), and increased transaminase levels (23\%). Cardiac events (18\%) occurred in five cases, including one case of ischemia and one case of Takotsubo cardiomyopathy. In spite of low toxicity, the proportion of patients who achieved an objective response was only $5 \%$, while $68 \%$ had stable disease and $27 \%$ showed progressive disease (137). A major hurdle in interpreting the data of the phase I study is that TargomiRs rapidly disappear from the circulation after injection. Moreover, immune reactions may occur shortly after the infusion of TargomiRs and may provide an explanation for the antitumor activity observed. The authors concluded that the unmet need of MM patients is very high. On the basis of these Phase I data, a combinatorial therapy seems to be the logical next step in TargomiR development.

Currently, the main barrier to implementing miRNA-based therapy is due to miRNA degradation by nucleases in the circulation and the lack of delivery systems that protect RNAs from nucleases and allow them into the tumor stroma without adverse effects. Exosomes are the physiological carriers of miRNAs, and their involvement in cell-to-cell communication provides an opportunity to deliver therapeutic cargo directly into the cytoplasm of target cells.

\section{CONCLUSIONS}

The alteration of miRNA expression is the results of exposure to carcinogens. Unlike chemical carcinogens, the toxicity of asbestos relies in its fibrous nature and persistence, and it involves mechanisms linked to increased ROS production. ROSinduced multiple somatic genetic and epigenetic changes may be required for the tumorigenic conversion of mesothelial cells. The epigenetic modulation of miRNAs occurs early during exposure, representing an adaptive event to defend the cells by activating the detoxifying mechanisms. However, persistent exposure to ROS overwhelms the miRNA-based adaptive response and the irreversible alterations associated with asbestos-induced DNA damage, contributing to cancer development. For example, miR-126 was reversibly expressed following asbestos exposure, while its irreversible downregulation resulted in the activation 
of the IRS1/PI3K/AKT pathway, which is a frequent event in human cancers as it plays a key role in cancer progression. Hence, its inhibition has become a promising approach to cancer therapy. Ectopic miR-126 inhibited IRS1, thus resulting in metabolic changes and consequent tumor suppression. The miRNA expression links environmental exposure to cancer onset, and this makes miRNAs candidate biomarkers for early detection of MM. Accordingly, the use of miRNAs alone or within a panel of other markers, which includes other miRNAs or molecules (proteins or DNA methylation) has been proposed to predict MM. However, either for the features of the disease or the non-specificity of the candidate miRNAs, the use of these biomarkers for early

\section{REFERENCES}

1. Lemen RA. Mesothelioma from asbestos exposures: epidemiologic patterns and impact in the United States. $J$ Toxicol Environ Health B Crit Rev. (2016) 19:250-65. doi: 10.1080/10937404.2016. 1195323

2. Nielsen LS, Bælum J, Rasmussen J, Dahl S, Olsen KE, Albin M, et al. Occupational asbestos exposure and lung cancer-a systematic review of the literature. Arch Environ Occup Health. (2014) 69:191-206. doi: 10.1080/19338244.2013.863752

3. Kettunen E, Hernandez-Vargas H, Cros MP, Durand G, Le CalvezKelm F, Stuopelyte K, et al. Asbestos-associated genome-wide DNA methylation changes in lung cancer. Int J Cancer. (2017) 141:2014-29. doi: $10.1002 / \mathrm{ijc} .30897$

4. Pascolo L, Gianoncelli A, Schneider G, Salomé M, Schneider M, Calligaro $\mathrm{C}$, et al. The interaction of asbestos and iron in lung tissue revealed by synchrotron-based scanning X-ray microscopy. Sci Rep. (2013) 3:1123. doi: 10.1038/srep01123

5. Lim SO, Gu JM, Kim MS, Kim HS, Park YN, Park CK, et al. Epigenetic changes induced by reactive oxygen species in hepatocellular carcinoma: methylation of the E-cadherin promoter. Gastroenterology. (2008) 135:212840. doi: 10.1053/j.gastro.2008.07.027

6. Tahiliani M, Koh KP, Shen Y, Pastor WA, Bandukwala H, Brudno Y, et al. Conversion of 5-methylcytosine to 5-hydroxymethylcytosine in mammalian DNA by MLL partner TET1. Science. (2009) 324:930-5. doi: $10.1126 /$ science. 1170116

7. Li W, Xu L. Epigenetic function of TET Family, 5-Methylcytosine, and 5-hydroxymethylcytosine in hematologic malignancies. Oncol Res Treat. (2019) 3:1-9. doi: 10.1159/000498947

8. Izzotti A, Larghero P, Longobardi M, Cartiglia C, Camoirano A, Steele VE, et al. Dose-responsiveness and persistence of microRNA expression alterations induced by cigarette smoke in mouse lung. Mutat Res. (2011) 717:9-16. doi: 10.1016/j.mrfmmm.2010.12.008

9. Benedetti S, Nuvoli B, Catalani S, Galati R. Reactive oxygen species a double-edged sword for mesothelioma. Oncotarget. (2015) 6:16848-65. doi: 10.18632 /oncotarget. 4253

10. Jing H, Lin H. Sirtuins in epigenetic regulation. Chem Rev. (2015) 115:235075. doi: $10.1021 / \mathrm{cr} 500457 \mathrm{~h}$

11. Sabari BR, Zhang D, Allis CD, Zhao Y. Metabolic regulation of gene expression through histone acylations. Nat Rev Mol Cell Biol. (2017) 18:90101. doi: $10.1038 / \mathrm{nrm} .2016 .140$

12. Kuzmichev A, Jenuwein T, Tempst P, Reinberg D. Different EZH2containing complexes target methylation of histone $\mathrm{H} 1$ or nucleosomal histone H3. Mol Cell. (2004) 14:183-93. doi: 10.1016/S1097-2765(04)00185-6

13. Trojer $\mathrm{P}$, Zhang J, Yonezawa $\mathrm{M}$, Schmidt A, Zheng $\mathrm{H}$, Jenuwein $\mathrm{T}$, et al. Dynamic histone H1 Isotype 4 methylation and demethylation by histone lysine methyltransferase G9a/KMT1C and the jumonji domaincontaining JMJD2/KDM4 proteins. J Biol Chem. (2009) 284:8395-405. doi: $10.1074 /$ jbc.M807818200 detection of MM is questionable. Significant changes in miRNA expression were detected only when the MM was manifested. Thus, the characterization of genome-wide DNA epigenetics may offer an opportunity to identify molecules of different classes that may improve the early diagnosis of a fatal type of neoplasia.

\section{AUTHOR CONTRIBUTIONS}

MT planned and wrote the manuscript. SG and FM acquired the data reported in the manuscript and participated in writing the paragraphs on miRNAs as biomarkers and therapeutic role. JN and LS edited, reviewed, and corrected the manuscript.

14. Niu Y, DesMarais TL, Tong Z, Yao Y, Costa M. Oxidative stress alters global histone modification and DNA methylation. Free Radic Biol Med. (2015) 82:22-8. doi: 10.1016/j.freeradbiomed.2015.01.028

15. Chen H, Ke Q, Kluz T, Yan Y, Costa M. Nickel ions increase histone H3 lysine 9 dimethylation and induce transgene silencing. Mol Cell Biol. (2006) 26:3728-37. doi: 10.1128/MCB.26.10.3728-3737.2006

16. Zhou X, Sun H, Ellen TP, Chen H, Costa M. Arsenite alters global histone H3 methylation. Carcinogenesis. (2008) 29:1831-6. doi: 10.1093/carcin/bgn063

17. Pinton G, Manente AG, Murer B, De Marino E, Mutti L, Moro L. PARP1 inhibition affects pleural mesothelioma cell viability and uncouples AKT/mTOR axis via SIRT1. J Cell Mol Med. (2013) 17:233-41. doi: $10.1111 /$ jcmm. 12000

18. Bhattacharjee P, Paul S, Bhattacharjee P. Risk of occupational exposure to asbestos, silicon and arsenic on pulmonary disorders: Understanding the genetic-epigenetic interplay and future prospects. Environ Res. (2016) 147:425-34. doi: 10.1016/j.envres.2016.02.038

19. Tomasetti M, Amati M, Nocchi L, Saccucci F, Strafella E, Staffolani S, et al. Asbestos exposure affects poly(ADP-ribose) polymerase-1 activity: role in asbestos-induced carcinogenesis. Mutagenesis. (2011) 26:585-91. doi: 10.1093/mutage/ger020

20. Ray Chaudhuri A, Nussenzweig A. The multifaceted roles of PARP1 in DNA repair and chromatin remodelling. Nat Rev Mol Cell Biol. (2017) 18:610-21. doi: $10.1038 / \mathrm{nrm} .2017 .53$

21. Deaton AM, Bird A. CpG islands and the regulation of transcription. Genes Dev. (2011) 25:1010-22. doi: 10.1101/gad.2037511

22. Chatterjee R, Vinson C. CpG methylation recruits sequence specific transcription factors essential for tissue specific gene expression. Biochim Biophys Acta. (2012) 1819:763-70. doi: 10.1016/j.bbagrm.2012.02.014

23. Moore LD, Le T, Fan G. DNA methylation and its basic function. Neuropsychopharmacology. (2013) 38:23-38. doi: 10.1038/npp.2012.112

24. Eckhardt F, Lewin J, Cortese R, Rakyan VK, Attwood J, Burger M, et al. DNA methylation profiling of human chromosomes 6, 20 and 22. Nat Genet. (2006) 38:1378-85. doi: 10.1038/ng1909

25. Weber M, Hellmann I, Stadler MB, Ramos L, Pääbo S, Rebhan M, et al. Distribution, silencing potential and evolutionary impact of promoter DNA methylation in the human genome. Nat Genet. (2007) 39:457-66. doi: 10.1038/ng1990

26. Xing X, Zhang B, Li D, Wang T. Comprehensive whole DNA methylome analysis by integrating MeDIP-seq and MRE-seq. Methods Mol Biol. (2018) 1708:209-46. doi: 10.1007/978-1-4939-7481-8_12

27. Bird A. The essentials of DNA methylation. Cell. (1992) 70:5-8. doi: 10.1016/0092-8674(92)90526-I

28. An J, Rao A, Ko M. TET family dioxygenases and DNA demethylation in stem cells and cancers. Exp Mol Med. (2017) 49:e323. doi: $10.1038 / \mathrm{emm} .2017 .5$

29. Choudhury SR, Ordaz J, Lo CL, Damayanti NP, Zhou F, Irudayaraj J. From the cover: zinc oxide nanoparticles-induced reactive oxygen species promotes multimodal cyto- and epigenetic toxicity. Toxicol Sci. (2017) 156:261-74. doi: 10.1093/toxsci/kfw252 
30. Portela A, Esteller M. Epigenetic modifications and human disease. Nat Biotechnol. (2010) 28:1057-68. doi: 10.1038/nbt.1685

31. Hitchins MP. Constitutional epimutation as a mechanism for cancer causality and heritability? Nat Rev Cancer. (2015) 15:625-34. doi: $10.1038 / \mathrm{nrc} 4001$

32. Bird A. Genetic determinants of the epigenome in development and cancer. Swiss Med Wkly. (2017) 147:w14523. doi: 10.4414/smw.2017.14523

33. Zealy RW, Wrenn SP, Davila S, Min KW, Yoon JH. microRNA-binding proteins: specificity and function. Wiley Interdiscip Rev RNA. (2017) 8:e1414. doi: 10.1002/wrna.1414

34. Kozomara A, Birgaoanu M, Griffiths-Jones S. miRBase: from microRNA sequences to function. Nucleic Acids Res. (2019) 47(D1):D155-62. doi: 10.1093/nar/gky1141

35. Morales S, Monzo M, Navarro A. Epigenetic regulation mechanisms of microRNA expression. Biomol Concepts. (2017) 8:203-12. doi: 10.1515/bmc-2017-0024

36. Calin GA, Sevignani C, Dumitru CD, Hyslop T, Noch E, Yendamuri S. Human microRNA genes are frequently located at fragile sites and genomic regions involved in cancers. Proc Natl Acad Sci USA. (2004) 101:2999-3004. doi: 10.1073/pnas.0307323101

37. Zhang B, Pan X, Cobb GP, Anderson TA. microRNAs as oncogenes and tumor suppressors. Dev Biol. (2007) 302:1-12. doi: 10.1016/j.ydbio.2006.08.028

38. Hinske LC, França GS, Torres HA, Ohara DT, Lopes-Ramos CM, Heyn J, et al. miRIAD-integrating microRNA inter- and intragenic data. Database. (2014) 2014:bau099. doi: 10.1093/database/bau099

39. Baskerville S, Bartel DP. Microarray profiling of microRNAs reveals frequent coexpression with neighboring miRNAs and host genes. RNA. (2005) 11:241-7. doi: 10.1261/rna.7240905

40. Liang Y, Ridzon D, Wong L, Chen C. Characterization of microRNA expression profiles in normal human tissues. BMC Genomics. (2007) 8:166. doi: 10.1186/1471-2164-8-166

41. Christensen BC, Houseman EA, Godleski JJ, Marsit CJ, Longacker JL, Roelofs $\mathrm{CR}$, et al. Epigenetic profiles distinguish pleural mesothelioma from normal pleura and predict lung asbestos burden and clinical outcome. Cancer Res. (2009) 69:227-34. doi: 10.1158/0008-5472.CAN-08-2586

42. Bosio M, Salvaterra E, Datturi F, Morbini P, Zorzetto M, Inghilleri S, et al. 5-hydroxymethylcytosine but not MTAP methylation status can stratify malignant pleural mesothelioma based on the lineage of origin. Multidiscip Respir Med. (2018) 13:27. doi: 10.1186/s40248-018-0137-4

43. Hama R, Watanabe Y, Shinada K, Yamada Y, Ogata Y, Yoshida $\mathrm{Y}$, et al. Characterization of DNA hypermethylation in two cases of peritoneal mesothelioma. Tumour Biol. (2012) 33:2031-40. doi: 10.1007/s13277-012-0462-8

44. Wang LM, Shi ZW, Wang JL, Lv Z, Du FB, Yang QB, et al. Diagnostic accuracy of BRCA1-associated protein 1 in malignant mesothelioma: a metaanalysis. Oncotarget. (2017) 8:68863-72. doi: 10.18632/oncotarget.20317

45. Betti M, Aspesi A, Biasi A, Casalone E, Ferrante D, Ogliara P, et al. CDKN2A and BAP1 germline mutations predispose to melanoma and mesothelioma. Cancer Lett. (2016) 378:120-30. doi: 10.1016/j.canlet.2016.05.011

46. Joseph NM, Chen YY, Nasr A, Yeh I, Talevich E, Onodera C, et al. Genomic profiling of malignant peritoneal mesothelioma reveals recurrent alterations in epigenetic regulatory genes BAP1, SETD2, and DDX3X. Mod Pathol. (2017) 30:246-54. doi: 10.1038/modpathol.2016.188

47. Campagne A, Lee MK, Zielinski D, Michaud A, Le Corre S, Dingli F, et al. BAP1 complex promotes transcription by opposing PRC1-mediated H2A ubiquitylation. Nat Commun. (2019) 10:348. doi: 10.1038/s41467-018-08255-X

48. Kukuyan AM, Sementino E, Kadariya Y, Menges CW, Cheung M, Tan Y, et al. Inactivation of Bap1 cooperates with losses of $\mathrm{Nf} 2$ and Cdkn2a to drive the development of pleural malignant mesothelioma in conditional mouse models. Cancer Res. (2019) 79:4113-23. doi: 10.1158/0008-5472.CAN-18-4093

49. Ohar JA, Cheung M, Talarchek J, Howard SE, Howard TD, Hesdorffer $\mathrm{M}$, et al. Germline BAP1 mutational landscape of asbestos-exposed malignant mesothelioma patients with family history of cancer. Cancer Res. (2016) 76:206-15. doi: 10.1158/0008-5472.CAN-1 5-0295

50. Betti M, Casalone E, Ferrante D, Aspesi A, Morleo G, Biasi A, et al. Germline mutations in DNA repair genes predispose asbestos-exposed patients to malignant pleural mesothelioma. Cancer Lett. (2017) 405:38-45. doi: 10.1016/j.canlet.2017.06.028

51. Testa JR, Cheung M, Pei J, Below JE, Tan Y, Sementino E, et al. Germline BAP1 mutations predispose to malignant mesothelioma. Nat Genet. (2011) 43:1022-5. doi: 10.1038/ng.912

52. Nasu M, Emi M, Pastorino S, Tanji M, Powers A, Luk H, et al. High Incidence of Somatic BAP1 alterations in sporadic malignant mesothelioma. J Thorac Oncol. (2015) 10:565-76. doi: 10.1097/JTO.0000000000000471

53. Yu M, Liang H, Fu Z, Wang X, Liao Z, Zhou Y, et al. BAP1 suppresses lung cancer progression and is inhibited by miR-31. Oncotarget. (2016) 7:13742-53. doi: 10.18632/oncotarget.7328

54. Ivanov SV, Goparaju CMV, Lopez P, Zavadil J, Toren-Haritan G, Rosenwald $\mathrm{S}$, et al. Pro-tumorigenic effects of miR-31 loss in mesothelioma. J Biol Chem. (2010) 285:22809-17. doi: 10.1074/jbc.M110.100354

55. Lin PC, Chiu YL, Banerjee S, Park K, Mosquera JM, Giannopoulou E, et al. Epigenetic repression of miR-31 disrupts androgen receptor homeostasis and contributes to prostate cancer progression. Cancer Res. (2013) 73:1232-44. doi: 10.1158/0008-5472.CAN-12-2968

56. Wei J, Wang Z, Wang Z, Yang Y, Fu C, Zhu J, et al. MicroRNA-31 function as a suppressor was regulated by epigenetic mechanisms in gastric cancer. Biomed Res Int. (2017) 2017:5348490. doi: 10.1155/2017/5348490

57. Matsumoto S, Nabeshima K, Hamasaki M, Shibuta T, Umemura T. Upregulation of microRNA-31 associates with a poor prognosis of malignant pleural mesothelioma with sarcomatoid component. Med Oncol. (2014) 31:303. doi: 10.1007/s12032-014-0303-2

58. Lo Russo G, Tessari A, Capece M, Galli G, de Braud F, Garassino $\mathrm{MC}$, et al. MicroRNAs for the diagnosis and management of malignant pleural mesothelioma: a literature review. Front Oncol. (2018) 8:650. doi: 10.3389/fonc.2018.00650

59. Tanaka N, Toyooka S, Soh J, Tsukuda K, Shien K, Furukawa M, et al. Downregulation of microRNA-34 induces cell proliferation and invasion of human mesothelial cells. Oncol Rep. (2013) 29:2169-74. doi: 10.3892/or.2013.2351

60. Kubo T, Toyooka S, Tsukuda K, Sakaguchi M, Fukazawa T, Soh J, et al. Epigenetic silencing of microRNA-34b/c plays an important role in the pathogenesis of malignant pleural mesothelioma. Clin Cancer Res. (2011) 17:4965-74. doi: 10.1158/1078-0432.CCR-10-3040

61. Misso G, Di Martino MT, De Rosa G, Farooqi AA, Lombardi A, Campani V, et al. Mir-34: a new weapon against cancer? Mol Ther Nucleic Acids. (2014) 3:e194. doi: 10.1038/mtna.2014.47

62. Sato H, Soh J, Aoe K, Fujimoto N, Tanaka S, Namba K, et al. Droplet digital PCR as a novel system for the detection of microRNA-34b/c methylation in circulating DNA in malignant pleural mesothelioma. Int J Oncol. (2019) 54:2139-48. doi: 10.3892/ijo.2019.4768

63. Cioce M, Ganci F, Canu V, Sacconi A, Mori F, Canino C, et al. Protumorigenic effects of mir-145 loss in malignant pleural mesothelioma. Oncogene. (2014) 33:5319-31. doi: 10.1038/onc.2013.476

64. Ye D, Shen Z, Zhou S. Function of microRNA-145 and mechanisms underlying its role in malignant tumor diagnosis and treatment. Cancer Manag Res. (2019) 11:969-79. doi: 10.2147/CMAR.S191696

65. Saito Y, Friedman JM, Chihara Y, Egger G, Chuang JC, Liang G. Epigenetic therapy upregulates the tumor suppressor microRNA-126 and its host gene EGFL7 in human cancer cells. Biochem Biophys Res Commun. (2009) 379:726-31. doi: 10.1016/j.bbrc.2008.12.098

66. Andersen M, Trapani D, Ravn J, Sørensen JB, Andersen CB, Grauslund $\mathrm{M}$, et al. Methylation-associated Silencing of microRNA-126 and its Host Gene EGFL7 in Malignant Pleural Mesothelioma. Anticancer Res. (2015) 35:6223-9.

67. Ebrahimi F, Gopalan V, Smith RA, Lam AK. miR-126 in human cancers: clinical roles and current perspectives. Exp Mol Pathol. (2014) 96:98-107. doi: 10.1016/j.yexmp.2013.12.004

68. Nichol D, Stuhlmann H. EGFL7: a unique angiogenic signaling factor in vascular development and disease. Blood. (2012) 119:1345-52. doi: 10.1182/blood-2011-10-322446

69. Hong G, Kuek V, Shi J, Zhou L, Han X, He W, et al. EGFL7: Master regulator of cancer pathogenesis, angiogenesis and an emerging mediator of bone homeostasis. J Cell Physiol. (2018) 233:8526-37. doi: 10.1002/jcp.26792

70. Nikolic I, Plate KH, Schmidt MHH. EGFL7 meets miRNA126: an angiogenesis alliance. J Angiogenes Res. (2010) 2:9. doi: $10.1186 / 2040-2384-2-9$ 
71. Lei H, Li H, Tian L, Li M, Xin Z, Zhang X, et al. Icariside II ameliorates endothelial dysfunction by regulating the MAPK pathway via miR126/SPRED1 in diabetic human cavernous endothelial cells. Drug Des Devel Ther. (2018) 12:1743-51. doi: 10.2147/DDDT.S166734

72. Yuan Y, Shen C, Zhao SL, Hu YJ, Song Y, Zhong QJ. MicroRNA-126 affects cell apoptosis, proliferation, cell cycle and modulates VEGF/TGF- $\beta$ levels in pulmonary artery endothelial cells. Eur Rev Med Pharmacol Sci. (2019) 23:3058-69. doi: 10.26355/eurrev_201904_17588

73. Chen H, Li L, Wang S, Lei Y, Ge Q, Lv N, et al. Reduced miR-126 expression facilitates angiogenesis of gastric cancer through its regulation on VEGF-A. Oncotarget. (2014) 5:11873-85. doi: 10.18632/oncotar get. 2662

74. Alhasan L. MiR-126 modulates angiogenesis in breast cancer by targeting VEGF-A -mRNA. Asian Pac J Cancer Prev. (2019) 20:193-7. doi: 10.31557/APJCP.2019.20.1.193

75. Song L, Li D, Gu Y, Wen ZM, Jie J, Zhao D, et al. MicroRNA-126 targeting PIK3R2 inhibits NSCLC A549 cell proliferation, migration, and invasion by regulation of PTEN/PI3K/AKT pathway. Clin Lung Cancer. (2016) 17:e6575. doi: 10.1016/j.cllc.2016.03.012

76. Chen SR, Cai WP, Dai XJ, Guo AS, Chen HP, Lin GS, et al. Research on miR-126 in glioma targeted regulation of PTEN/PI3K/Akt and MDM2-p53 pathways. Eur Rev Med Pharmacol Sci. (2019) 23:3461-70. doi: 10.26355/eurrev_201904_17711

77. Hamada S, Satoh K, Fujibuchi W, Hirota M, Kanno A, Unno J, et al. MiR-126 acts as a tumor suppressor in pancreatic cancer cells via the regulation of ADAM9. Mol Cancer Res. (2012) 10:3-10. doi: 10.1158/1541-7786.MCR-11-0272

78. Wang CZ, Yuan P, Li Y. MiR-126 regulated breast cancer cell invasion by targeting ADAM9. Int J Clin Exp Pathol. (2015) 8:6547-53.

79. Xiang LY, Ou HH, Liu XC, Chen ZJ, Li XH, Huang Y, et al. Loss of tumor suppressor miR-126 contributes to the development of hepatitis B virus-related hepatocellular carcinoma metastasis through the upregulation of ADAM9. Tumour Biol. (2017) 39:1010428317709128. doi: $10.1177 / 1010428317709128$

80. Santarelli L, Strafella E, Staffolani S, Amati M, Emanuelli M, Sartini D, et al. Association of MiR-126 with soluble mesothelin-related peptides, a marker for malignant mesothelioma. PLoS ONE. (2011) 6:e18232. doi: 10.1371/journal.pone.0018232

81. Tomasetti M, Staffolani S, Nocchi L, Neuzil J, Strafella E, Manzella $\mathrm{N}$, et al. Clinical significance of circulating miR-126 quantification in malignant mesothelioma patients. Clin Biochem. (2012) 45:575-81. doi: 10.1016/j.clinbiochem.2012.02.009

82. Andersen M, Grauslund M, Ravn J, Sørensen JB, Andersen CB, SantoniRugiu E. Diagnostic potential of miR-126, miR-143, miR-145, and miR652 in malignant pleural mesothelioma. J Mol Diagn. (2014) 16:418-30. doi: 10.1016/j.jmoldx.2014.03.002

83. Santarelli L, Staffolani S, Strafella E, Nocchi L, Manzella N, Grossi P, et al. Combined circulating epigenetic markers to improve mesothelin performance in the diagnosis of malignant mesothelioma. Lung Cancer. (2015) 90:457-64. doi: 10.1016/j.lungcan.2015.09.021

84. Micolucci L, Akhtar MM, Olivieri F, Rippo MR, Procopio AD. Diagnostic value of microRNAs in asbestos exposure and malignant mesothelioma: systematic review and qualitative meta-analysis. Oncotarget. (2016) 7:5860637. doi: 10.18632/oncotarget.9686

85. De Santi C, Melaiu O, Bonotti A, Cascione L, Di Leva G, Foddis R, et al. Deregulation of miRNAs in malignant pleural mesothelioma is associated with prognosis and suggests an alteration of cell metabolism. Sci Rep. (2017) 7:3140. doi: 10.1038/s41598-017-02694-0

86. Santarelli L, Gaetani S, Monaco F, Bracci M, Valentino M, Amati $\mathrm{M}$, et al. Four-miRNA signature to identify asbestos-related lung malignancies. Cancer Epidemiol. Biomarkers Prev. (2019) 28:119-26. doi: 10.1158/1055-9965.EPI-18-0453

87. Jiang R, Zhang C, Liu G, Gu R, Wu H. MicroRNA-126 inhibits proliferation, migration, invasion, and EMT in osteosarcoma by targeting ZEB1. J Cell Biochem. (2017) 118:3765-74. doi: 10.1002/jcb.26024

88. Kong R, Ma Y, Feng J, Li S, Zhang W, Jiang J, et al. The crucial role of miR126 on suppressing progression of esophageal cancer by targeting VEGF-A. Cell Mol Biol Lett. (2016) 21:3. doi: 10.1186/s11658-016-0004-2
89. Liu R, Zhang YS, Zhang S, Cheng ZM, Yu JL, Zhou S, et al. MiR-126-3p suppresses the growth, migration and invasion of NSCLC via targeting CCR1. Eur Rev Med Pharmacol Sci. (2019) 23:679-89. doi: 10.26355/eurrev_201901_16881

90. Tomasetti M, Nocchi L, Staffolani S, Manzella N, Amati M, Goodwin J, et al. MicroRNA-126 suppresses mesothelioma malignancy by targeting IRS1 and interfering with the mitochondrial function. Antioxid Redox Signal. (2014) 21:2109-25. doi: 10.1089/ars.2013.5215

91. Tomasetti M, Monaco F, Manzella N, Rohlena J, Rohlenova K, Staffolani S, et al. MicroRNA-126 induces autophagy by altering cell metabolism in malignant mesothelioma. Oncotarget. (2016) 7:36338-52. doi: 10.18632/oncotarget.8916

92. Zhang Y, Wang X, Xu B, Wang B, Wang Z, Liang Y, et al. (2013). Epigenetic silencing of miR-126 contributes to tumor invasion and angiogenesis in colorectal cancer. Oncol Rep. 30:1976-84. doi: 10.3892/or.2013.2633

93. Moradi Sarabi M, Zahedi SA, Pajouhi N, Khosravi P, Bagheri S, Ahmadvand $\mathrm{H}$, et al. The effects of dietary polyunsaturated fatty acids on miR-126 promoter DNA methylation status and VEGF protein expression in the colorectal cancer cells. Genes Nutr. (2018) 13:32. doi: 10.1186/s12263-018-0623-5

94. Zhang Y, Yang P, Sun T, Li D, Xu X, Rui Y, et al. miR-126 and miR$126^{*}$ repress recruitment of mesenchymal stem cells and inflammatory monocytes to inhibit breast cancer metastasis. Nat Cell Biol. (2013) 15:28494. doi: $10.1038 /$ ncb2690

95. Liu F, Zhang H, Lu S, Wu Z, Zhou L, Cheng Z, et al. Quantitative assessment of gene promoter methylation in non-small cell lung cancer using methylation-sensitive high-resolution melting. Oncol Lett. (2018) 15:763948. doi: 10.3892/ol.2018.8321

96. Du J, Zhang L. Integrated analysis of DNA methylation and microRNA regulation of the lung adenocarcinoma transcriptome. Oncol Rep. (2015) 34:585-94. doi: 10.3892/or.2015.4023

97. Liu R, Gu J, Jiang P, Zheng Y, Liu X, Jiang X, et al. DNMT1-microRNA126 epigenetic circuit contributes to esophageal squamous cell carcinoma growth via ADAM9-EGFR-AKT signaling. Clin Cancer Res. (2015) 21:854-63. doi: 10.1158/1078-0432.CCR-14-1740

98. Cui H, Mu Y, Yu L, Xi YG, Matthiesen R, Su X, et al. Methylation of the miR126 gene associated with glioma progression. Fam Cancer. (2016) 15:317-24. doi: 10.1007/s10689-015-9846-4

99. Zampieri M, Guastafierro T, Calabrese R, Ciccarone F, Bacalini MG, Reale A, et al. ADP-ribose polymers localized on Ctcf-Parp1-Dnmt1 complex prevent methylation of Ctcf target sites. Biochem J. (2012) 441:645-52. doi: 10.1042/BJ20111417

100. Zampieri M, Passananti C, Calabrese R, Perilli M, Corbi N, De Cave $\mathrm{F}$, et al. Parp1 localizes within the Dnmt1 promoter and protects its unmethylated state by its enzymatic activity. PLoS ONE. (2009) 4:e4717. doi: 10.1371/journal.pone.0004717

101. Clements EG, Mohammad HP, Leadem BR, Easwaran H, Cai Y, Van Neste L, et al. DNMT1 modulates gene expression without its catalytic activity partially through its interactions with histone-modifying enzymes. Nucleic Acids Res. (2012) 40:4334-46. doi: 10.1093/nar/gks031

102. De Vos M, El Ramy R, Quénet D, Wolf P, Spada F, Magroun N, et al. Poly(ADP-ribose) polymerase 1 (PARP1) associates with E3 ubiquitinprotein ligase UHRF1 and modulates UHRF1 biological functions. J Biol Chem. (2014) 289:16223-38. doi: 10.1074/jbc.M113.527424

103. Wang X, Wang S, Liu W, Wang T, Wang J, Gao X, et al. Epigenetic upregulation of miR-126 induced by heat stress contributes to apoptosis of rat cardiomyocytes by promoting Tomm40 transcription. J Mol Cell Cardiol. (2019) 129:39-48. doi: 10.1016/j.yjmcc.2018.10.005

104. Iorio MV, Piovan C, Croce CM. Interplay between microRNAs and the epigenetic machinery: an intricate network. Biochim Biophys Acta. (2010) 1799:694-701. doi: 10.1016/j.bbagrm.2010.05.005

105. Lee KH, Lotterman C, Karikari C, Omura N, Feldmann G, Habbe N, et al. Epigenetic silencing of MicroRNA miR-107 regulates cyclin-dependent kinase 6 expression in pancreatic cancer. Pancreatology. (2009) 9:293-301. doi: 10.1159/000186051

106. Pass HI, Goparaju C, Ivanov S, Donington J, Carbone M, Hoshen M, et al. hsa-miR-29c* is linked to the prognosis of malignant pleural mesothelioma. Cancer Res. (2010) 70:1916-24. doi: 10.1158/0008-5472.CAN-09-3993 
107. Fabbri M, Garzon R, Cimmino A, Liu Z, Zanesi N, Callegari E, et al. MicroRNA-29 family reverts aberrant methylation in lung cancer by targeting DNA methyltransferases 3A and 3B. Proc Natl Acad Sci USA. (2007) 104:15805-10. doi: 10.1073/pnas.0707628104

108. Alamoudi AA, Alnoury A, Gad H. miRNA in tumour metabolism and why could it be the preferred pathway for energy reprograming. Brief Funct Genomics. (2018) 17:157-69. doi: 10.1093/bfgp/elx023

109. Tomasetti M, Amati M, Santarelli L, Neuzil J. MicroRNA in metabolic reprogramming and their role in tumorigenesis. Int J Mol Sci. (2016) 17:E754. doi: 10.3390/ijms17050754

110. Zhao X, Zhu D, Lu C, Yan D, Li L, Chen Z. MicroRNA-126 inhibits the migration and invasion of endometrial cancer cells by targeting insulin receptor substrate 1. Oncol Lett. (2016) 11:1207-12. doi: 10.3892/ol.2015.4001

111. Hekmatimoghaddam S, Dehghani Firoozabadi A, Zare-Khormizi MR, Pourrajab F. Sirt1 and Parpl as epigenome safeguards and microRNAs as SASP-associated signals, in cellular senescence and aging. Ageing Res Rev. (2017) 40:120-41. doi: 10.1016/j.arr.2017.10.001

112. Bungard D, Fuerth BJ, Zeng PY, Faubert B, Maas NL, Viollet B, et al. Signaling kinase AMPK activates stress-promoted transcription via histone H2B phosphorylation. Science. (2010) 329:1201-5. doi: 10.1126/science.1191241

113. Kirschner MB, Cheng YY, Armstrong NJ, Lin RC, Kao SC, Linton A, et al. MiR-score: a novel 6-microRNA signature that predicts survival outcomes in patients with malignant pleural mesothelioma. Mol Oncol. (2015) 9:715-26. doi: 10.1016/j.molonc.2014.11.007

114. Chen Z, Gaudino G, Pass HI, Carbone M, Yang H. Diagnostic and prognostic biomarkers for malignant mesothelioma: an update. Transl Lung Cancer Res. (2017) 6:259-69. doi: 10.21037/tlcr.2017.05.06

115. Mozzoni P, Ampollini L, Goldoni M, Alinovi R, Tiseo M, Gnetti L, et al. MicroRNA expression in malignant pleural mesothelioma and asbestosis: a pilot study. Dis Markers. (2017) 2017:9645940. doi: 10.1155/2017/9645940

116. Schelch K, Kirschner MB, Williams M, Cheng YY, van Zandwijk N, Grusch $\mathrm{M}$, et al. A link between the fibroblast growth factor axis and the miR-16 family reveals potential new treatment combinations in mesothelioma. $\mathrm{Mol}$ Oncol. (2018) 12:58-73. doi: 10.1002/1878-0261.12150

117. Weber DG, Johnen G, Bryk O, Jöckel KH, Brüning T. Identification of miRNA-103 in the cellular fraction of human peripheral blood as a potential biomarker for malignant mesothelioma-a pilot study. PLoS ONE. (2012) 7:e30221. doi: 10.1371/journal.pone.0030221

118. Busacca S, Germano S, De Cecco L, Rinaldi M, Comoglio F, Favero F, et al. MicroRNA signature of malignant mesothelioma with potential diagnostic and prognostic implications. Am J Respir Cell Mol Biol. (2010) 42:312-19. doi: 10.1165/rcmb.2009-0060OC

119. Birnie KA, Yip YY, Ng DC, Kirschner MB, Reid G, Prêle CM, et al. Loss of mir-223 and jnk signaling contribute to elevated stathmin in malignant pleuralmesothelioma. Mol Cancer Res. (2015) 13:1106-18. doi: 10.1158/1541-7786.MCR-14-0442

120. Kirschner MB, Cheng YY, Badrian B, Kao SC, Creaney J, Edelman JJ, et al. Increased circulating miR-625-3p: a potential biomarker for patients with malignant pleural mesothelioma. J Thorac Oncol. (2012) 7:1184-91. doi: 10.1097/JTO.0b013e3182572e83

121. Cheng YY, Wright CM, Kirschner MB, Williams M, Sarun KH, Sytnyk $\mathrm{V}$, et al. KCa1.1, a calcium-activated potassium channel subunit alpha 1 , is targeted by miR-17-5p and modulates cell migration in malignant pleural mesothelioma. Mol Cancer. (2016) 15:44. doi: 10.1186/s12943-0160529-z

122. Williams M, Kirschner MB, Cheng YY, Hanh J, Weiss J, Mugridge $\mathrm{N}$, et al. miR-193a- $3 \mathrm{p}$ is a potential tumor suppressor in malignant pleural mesothelioma. Oncotarget. (2015) 6:23480-95. doi: 10.18632/oncotarget.4346

123. Mairinger FD, Werner R, Flom E, Schmeller J, Borchert S, Wessolly M, et al. miRNA regulation is important for DNA damage repair and recognition in malignant pleural mesothelioma. Virchows Arch. (2017) 470:627-37. doi: $10.1007 / \mathrm{s} 00428-017-2133-\mathrm{z}$
124. De Santi C, Vencken S, Blake J, Haase B, Benes V, Gemignani $\mathrm{F}$, et al. Identification of MiR- $21-5 \mathrm{p}$ as a functional regulator of mesothelin expression using MicroRNA capture affinity coupled with next generation sequencing. PLoS ONE. (2017) 12:e0170999. doi: 10.1371/journal.pone.0170999

125. Garofalo M, Quintavalle C, Romano G, Croce CM, Condorelli G. miR221/222 in cancer: their role in tumor progression and response to therapy. Curr Mol Med. (2012) 12:27-33. doi: 10.2174/156652412798376170

126. Nymark P, Guled M, Borze I, Faisal A, Lahti L, Salmenkivi K, et al. Integrative analysis of microRNA, mRNA and aCGH data reveals asbestosand histology-related changes in lung cancer. Genes Chromosomes Cancer. (2011) 50:585-97. doi: 10.1002/gcc.20880

127. Lovat F, Fassan M, Sacchi D, Ranganathan P, Palamarchuk A, Bill M, et al. Knockout of both miR-15/16 loci induces acute myeloid leukemia. Proc Natl Acad Sci USA. (2018) 115:13069-74. doi: 10.1073/pnas.1814980115

128. Mei Q, Li X, Zhang $\mathrm{K}, \mathrm{Wu} \mathrm{Z}, \mathrm{Li} \mathrm{X}$, Meng Y, et al. Genetic and methylation-induced loss of miR-181a2/181b2 within chr9q33.3 facilitates tumor growth of cervical cancer through the PIK3R3/Akt/FoxO signaling pathway. Clin Cancer Res. (2017) 23:575-86. doi: 10.1158/1078-0432.CCR16-0303

129. Weber DG, Brik A, Casjens S, Burek K, Lehnert M, Pesch B, et al. Are circulating microRNAs suitable for the early detection of malignant mesothelioma? Results from a nested case-control study. BMC Res Notes. (2019) 12:77. doi: 10.1186/s13104-019-4113-7

130. Cristaudo A, Bonotti A, Guglielmi G, Fallahi P, Foddis R. Serum mesothelin and other biomarkers: what have we learned in the last decade? J Thorac Dis. (2018) 10(Suppl 2): S353-9. doi: 10.21037/jtd.2017.10.132

131. Tomasetti M, Santarelli L. Biomarkers for early detection of malignant mesothelioma: diagnostic and therapeutic application. Cancers. (2010) 2:523-48. doi: 10.3390/cancers2020523

132. Hollevoet K, Reitsma JB, Creaney J, Grigoriu BD, Robinson BW, Scherpereel A, et al. Serum mesothelin for diagnosing malignant pleural mesothelioma: an individual patient data meta-analysis. J Clin Oncol. (2012) 30:1541-9. doi: 10.1200/JCO.2011.39.6671

133. Ban CJ, Shi HZ, Zhang YH. Improvement of malignant pleural mesothelioma prognosis: early diagnosis and multimodality treatment. Chin Med J. (2017) 130:1-3. doi: 10.4103/0366-6999.196585

134. Witwer KW. Circulating microRNA biomarker studies: pitfalls and potential solutions. Clin Chem. (2015) 61:56-63. doi: 10.1373/clinchem.2014.221341

135. Amr KS, Abdelmawgoud H, Ali ZY, Shehata S, Raslan HM. Potential value of circulating microRNA-126 and microRNA-210 as biomarkers for type 2 diabetes with coronary artery disease. Br J Biomed Sci. (2018) 75:82-7. doi: 10.1080/09674845.2017.1402404

136. Wu H, Xiao Z, Wang K, Liu W, Hao Q. MiR-145 is downregulated in human ovarian cancer and modulates cell growth and invasion by targeting p70S6K1 and MUC1. Biochem Biophys Res Commun. (2013) 441:693-700. doi: 10.1016/j.bbrc.2013.10.053

137. van Zandwijk N, Pavlakis N, Kao SC, Linton A, Boyer MJ, Clarke $S$, et al. Safety and activity of microRNA-loaded minicells in patients with recurrent malignant pleural mesothelioma: a first-in-man, phase 1, open-label, dose-escalation study. Lancet Oncol. (2017) 18:1386-96. doi: 10.1016/S1470-2045(17)30621-6

Conflict of Interest: The authors declare that the research was conducted in the absence of any commercial or financial relationships that could be construed as a potential conflict of interest.

Copyright (c) 2019 Tomasetti, Gaetani, Monaco, Neuzil and Santarelli. This is an open-access article distributed under the terms of the Creative Commons Attribution License (CC BY). The use, distribution or reproduction in other forums is permitted, provided the original author(s) and the copyright owner(s) are credited and that the original publication in this journal is cited, in accordance with accepted academic practice. No use, distribution or reproduction is permitted which does not comply with these terms. 